\title{
Acoso político: \\ Experiencias de vicealcaldesas en su participación política en el período del 2010-2020
}

Political harassment: the experiences of female deputy mayors in their political intervention during the $2010-2020$ period

ISSN 2071-8748

E-ISSN 2218-3345

(c) (P)

DOI: https://doi.org/10.5377/entorno.v0i69.9571

URI: http://hdl.handle.net/11298/1165
Katherine Fernández-Rojas Licenciada en Género y Desarrollo por la Universidad Nacional Bachiller en Inglés de la Universidad Nacional Centro de formación: Universidad Nacional de Costa Rica Consultora de la Unión Europea con el Programa EUROsociAL kaferrox@gmail.com ORCID: https://orcid.org/0000-0002-8487-0753

Recibido: 9 de enero 2020 Aceptado: 27 de junio de 2020

\section{Resumen}

Las expresiones de acoso político quedan manifestadas en las entrevistas realizadas a las vicealcaldesas. El acoso político tiene la finalidad de obstruir la participación política de las mujeres en Costa Rica. La participación política de las mujeres ha estado sujeta por una constante lucha por el derecho a acceder al ámbito público, sin embargo, la lucha continúa en garantizar espacios libres de discriminación hacia ellas, con el fin de garantizar su la plena participación y lograr una igualdad real.

\section{Palabras clave}

Mujeres - Acoso político - Costa Rica; Discriminación de género - Costa Rica; Sexismo - Costa Rica; Mujeres - Participación política - Costa Rica; Mujeres - Derechos políticos - Costa Rica.

\section{Abstract}

The expressions of political harassment are manifested in the interviews conducted with the female deputy mayors. The purpose of political harassment is to obstruct the political participation of women in Costa Rica. Their political participation has been subjected by a constant struggle for the right to have access to the public field, however, the struggle continues in order to guarantee their full participation and to achieve real equality.

\section{Keywords}

Women - Political harassment - Costa Rica; Gender discrimination - Costa Rica; Sexism - Costa Rica; Women - Political participation - Costa Rica; Women - Political rights - Costa Rica. 
"Las mujeres se van a topar con muchos obstáculos en el camino, eso de que es mujer, los hombres a veces tratan de aminorar o desacreditar su potencial solo por ser mujer"

(Testimonio de Vicealcaldesa)

\section{Introducción}

A través de la historia, la participación política de las mujeres ha sido caracterizada por una constante lucha para optar por puestos en un ámbito público. Si bien han existido avances importantes a escala nacional en la defensa de los derechos políticos de las mujeres, como por ejemplo, la implementación de la Ley 7.653 , la cual establece una cuota de un $40 \%$ de participación de las mujeres en las listas de las asambleas de distrito, cantonales y provinciales (Art. 60, 1996), y posteriormente la Ley 8.765 , en el 2009, donde establece el principio de igualdad, no discriminación y paridad como medidas para garantizar el acceso de las mujeres en la política, sin embargo, aún no se garantiza el disfrute pleno de los derechos políticos de las mujeres. A pesar de la importancia de la igualdad formal para garantizar el acceso y la participación política de las mujeres, no es suficiente para la garantía de sus derechos políticos. Existen barreras, culturales, personales, económicas, socioculturales, que permean en el disfrute de su derecho a participar en la política sin ningún tipo de discriminación, como, por ejemplo, el acoso político.

El acoso político son expresiones discriminatorias cuya única finalidad es obstaculizar la participación política de las mujeres, con el fin de que desistan de sus labores en los tres momentos de su participación: la postulación, la campaña y el ejercicio de su cargo. Torres (2010) señala el acoso político como "...acciones de violencia contra las mujeres que ejercen representación política y tienen su base en diversas formas de discriminación (descalificación, estigmatización, manipulación y hostigamiento, entre otras) que enfrentan las mujeres que ocupan puestos de elección popular en el nivel local" (p. 28).

Son diversas las expresiones discriminatorias que las mujeres enfrentan en su participación, ya sean de forma directa como indirecta. Por lo tanto, sin la plena participación de las mujeres en la política no se puede hablar de democracia. No se debe de garantizar únicamente el acceso de las mujeres en la política, sino, es necesario velar que la participación no esté caracterizada por conductas discriminatorias durante su proceso político. Por consiguiente, Escalante y Méndez (2011) señalan que el acoso político es:

un acto o conjunto de actos cometidos por una persona, por sí o a través de terceros, en contra de una mujer o de su familia, con el propósito de impedir y/o inducir a una acción u omisión, en el cumplimiento de sus funciones, derechos o deberes, mediante actos de presión a través de persecución, hostigamiento $o$ amenazas efectuadas por cualquier medio (p. 15).

El acoso político implica una actitud violenta hacia las mujeres que laboran en la esfera pública, donde se enfrentan a expresiones discriminatorias de diversas formas que reducen la oportunidad de las mujeres para trabajar en este espacio, las limita y cohesiona para que deserten de su participación política.

Por todo lo anterior, se presentarán a continuación detalles de la investigación denominada "Acoso político: experiencias de vicealcaldesas en su participación política en el período del 2010-2020", con el fin de evidenciar y visibilizar la situación de la participación política de las mujeres, y que, a su vez, permita generar estrategias para prevenir, atender y sancionar el acoso político.

\section{Metodología}

La investigación anteriormente mencionada se caracteriza por ser cualitativa, con el fin de analizar las diversas expresiones de discriminación hacia las mujeres en la política, asimismo, analizar las repercusiones hacia ellas tanto en lo personal como profesional. La recolección de datos se desarrolla sin medición numérica, con el propósito de utilizar preguntas abiertas para interpretar la información brindada por las participantes. 
Por otro lado, el tipo de investigación es exploratoria debido a la escaza información e investigación sobre el acoso político, por lo tanto, permitió explorar por medio de sus vivencias, las diversas manifestaciones de acoso político que han tenido que enfrentar en los tres momentos de la participación política. Asimismo, la investigación tuvo como eje transversal la perspectiva de género, con el fin de reconocer las relaciones de poder entre hombres y mujeres en el ámbito público.

Por consiguiente, se realiza una entrevista semiestructurada dentro del enfoque cualitativo, con el propósito de aplicar preguntas abiertas para generar una comunicación abierta con las participantes sobre sus experiencias en un puesto de elección popular. Además, se utiliza el principio de saturación, el cual permitió no establecer un número de entrevistas y se enfocó en recolectar información hasta que no hubiese ningún dato nuevo. El principio de saturación permite hacer análisis de la información que se recolecta en cada entrevista; y si existe algún dato nuevo, es necesario continuar con su análisis y con las entrevistas.

La población de estudio fueron las vicealcaldesas electas del periodo del 2010 al 2020. En total se completaron 18 entrevistas, de las cuales siete correspondieron al periodo electoral del 2010- al 2016, y 11 entrevistas correspondieron al periodo 2016-2020. La edad promedio de las vicealcaldesas entrevistadas estuvo entre los 28 y los 63 años. Las entrevistas realizadas para el periodo anterior corresponden a tres cantones de Alajuela, dos cantones de Heredia, un cantón de San José y un cantón de Limón. Para el periodo actual, corresponden a dos cantones de Alajuela, tres cantones de San José, cuatro cantones de Heredia, un cantón de Limón y e1 cantón de Puntarenas. Los partidos políticos a los cuales pertenecen las participantes fueron variados; se destacan el Partido Liberación Nacional (PLN), el Frente Amplio (FA), el Partido Acción Ciudadana (PAC) y el Partido Unión Social Cristiana (PUSC).

\section{Resultados y aportes}

El acceso a la participación política de las mujeres ha sido una lucha constante para no únicamente acceder, sino para mantenerse en un puesto de elección popular. Por lo anterior, es fundamental evidenciar las diversas expresiones discriminatorias hacia las mujeres en su primer momento de la participación política: la postulación.
A pesar de los esfuerzos por proveer espacios a las mujeres en la política como el principio de paridad y alternancia, se sigue viendo a la mujer como una persona opcional en la política y su incorporación evidencia únicamente el cumplimiento de una normativa. Los espacios otorgados a ellas no son puestos que representan poder donde puedan tomar decisiones, como por ejemplo una alcaldía. Es decir, las vicealcaldesas indicaron haber sido buscadas para formar parte de la papeleta, pero directamente como vicealcaldesas y no como alcaldesas, a pesar de que dos de las entrevistadas indicaron haber externado su interés en ser candidatas a alcaldesas. Estos dos testimonios mencionaron que debido a "juegos sucios" de la política aceptaron su postulación como vicealcaldesas. La situación anteriormente señalada evidencia un cumplimiento de la normativa, pero relegando a las mujeres a segundos puestos. "Han dicho: 'Es que como hay que rellenar el campo de las mujeres'." Es vital indicar que la percepción de la mayoría de las entrevistadas ha sido que su participación en la política como vicealcaldesas fue una estrategia, ya que consideran que las invitaron a formar parte de la papeleta no solo para el cumplimiento de la normativa, sino también fue debido a su trayectoria activa en la comunidad, lo cual mencionaron que fue una forma de atraer votos para el partido. Debido a lo anterior, se detallan los siguientes dos testimonios:

...Eso fue una estrategia. Me buscó porque yo conocía mucha gente, que casi casi, el otro con el que yo me había postulado, me dijo que por tres votos no ganamos. Entonces él dijo a (nombre): "La voy a llevar de primera vicealcaldesa...".

La gente me decía: “Es que el alcalde la utilizó a usted para ganar, pero él lo que quería era que estuviera el segundo vicealcalde con él".

Por consiguiente, el factor económico ha sido un obstáculo para que las mujeres decidan postularse a un puesto de elección popular, por lo cual, indicaron, han tenido que negociar para acceder a un puesto político.

A uno le pasa en mente de poderse postular, pero es difícil. A veces, hay muchos obstáculos; $y$, a veces, se echa para atrás en algunas cositas... El obstáculo viene de la parte económica. Si yo tuviera dinero que me sobrara, no lo pensaría mucho para postularme en cualquier puesto, pero 
todo equivale un precio. Para usted inscribir una papeleta, necesita dinero; y a veces una no lo tiene. Esa parte es complicada y buscar financiamiento no es tan fácil"

Por otro lado, las diversas manifestaciones discriminatorias también fueron expresadas por las vicealcaldesas en el segundo momento de su participación política: la campaña, el cual fue descrito como un proceso bastante duro, hostil, de ataques, entre otras características no positivas para ellas. Las diversas expresiones discriminatorias hacia las vicealcaldesas durante el periodo de campaña fueron consideradas por las participantes como algo propio de la política. Se logró evidenciar una normalización de las calumnias, los chistes, ataques y las mentiras, entre otras, por ende, se señala el siguiente testimonio: "Te desacreditan a nivel personal; $y$ eso es lo que tenés que pagar por incidir a nivel cantonal". Estas creencias han generado en las participantes cuestionar si deseaban participar en un puesto de elección popular y, por supuesto, si deseaban continuar con el proceso, ya que los ataques no fueron únicamente hacia ellas, sino también involucraban a la familia.

Las manifestaciones discriminatorias hacia las vicealcaldesas no únicamente fueron expresadas de manera verbal, sino también se manifestaron de manera digital, es decir, por redes sociales, haciendo referencia al cuerpo de la entrevistada donde se creó un (meme) con la siguiente frase: "Cara bonita, culo flojo". Asimismo, se evidenciaron ataques hacia las vicealcaldesas en el proceso de campaña relacionados con la edad de las candidatas, por lo que se puede destacar el siguiente comentario: "Ah, es que usted es muy joven, es una mujer muy bonita".

Por todo lo anterior, el proceso de campaña, a pesar de que las entrevistadas consideraron que era un espacio importante para dar a conocer sus propuestas y tener un acercamiento con la población y conocer las necesidades, fue marcado por un ambiente hostil y de ataque con el fin de obstaculizar su participación política y provocar la renuncia de su postulación. A pesar de los diversos ataques, las vicealcaldesas decidieron continuar con su proceso político teniendo en cuenta la responsabilidad que tenían con el pueblo.

Por consiguiente, el último momento de la participación política: el ejercicio del cargo, estuvo caracterizado de igual manera por un ambiente hostil y por discriminaciones tanto de manera directa como indirecta. Es importante señalar diferentes situaciones que enfrentaron y siguen enfrentando las vicealcaldesas. Primeramente, existe una gran incertidumbre por conocer las funciones que deberán de ejecutar debido a que, en el Código Municipal, en el artículo 14 se establece que:

El (la) vicealcalde primero realizará las funciones administrativas y operativas que el alcalde titular le asigne; además, sustituirá, de pleno derecho, al alcalde municipal en sus ausencias temporales y definitivas, con las mismas responsabilidades y competencias de este durante el plazo de la sustitución.

Debido a lo anterior, la designación de funciones queda sujeta a la persona que ejerce la alcaldía; y teniendo en cuenta que la mayoría son hombres, las vicealcaldesas han enfrentado dificultades para que se les asignen funciones correspondientes a su puesto. Por lo tanto, han expresado incertidumbre, ya que no conocen qué pueden hacer como vicealcaldesas y qué no les compete. "He sentido incertidumbre de qué debo hacer y qué no debo hacer como vicealcaldesa. No sé si puedo tomar decisiones o no". Esta situación ha provocado que no se le asignen funciones acordes con el puesto e incluso que no le den labores por realizar. Por lo anterior, las vicealcaldesas han tenido que recurrir al recurso de amparo, como un medio para hacer valer sus derechos políticos, y han dejado saber que existe un vacío legal en el Código Electoral referente a las funciones de la vicealcaldía.

Además, las vicealcaldesas han expresado como obstáculo para ejercer su cargo la no asignación de espacio físico y de equipo para laborar, por lo cual también han optado por recursos de amparo para velar por su derecho a laborar en un puesto de elección popular. Por otro lado, se destaca como información importante evidenciada en las entrevistas y señaladas de manera directa por las vicealcaldesas, las áreas que se les designa para laborar. Por lo anterior las áreas en las cuales se están desempeñando las vicealcaldesas la social, cultural, recursos humanos. "Por lo general, si pregunta a otras vicealcaldesas, se les da el área social y recursos humanos. Yo considero que por la misma mentalidad machista... Me parecía que eso era machismo legítimo, siempre relacionándola con el cuido y la educación". 
Esta situación evidencia el papel tradicionalmente femenino y su deber ser, relacionando a la mujer con el cuido de otras personas, la cual influye en la designación de las funciones para las vicealcaldesas, ya que no se les asignan áreas operativas aun cuando en el Código Electoral lo indica.

Asimismo, se desea destacar, como manifestación discriminatoria, que conlleva a generar un obstáculo para que las mujeres continúen en su puesto político; es el ambiente hostil que han enfrentado y enfrentan las vicealcaldesas por parte de la figura del alcalde, el personal municipal y el concejo municipal. Este ambiente hostil y las diversas manifestaciones de acoso político son expresados debido a ideologías machistas: "Muchas veces tenía actitudes de burla hacia mí, una forma solapada de agresión hacia mí. No me pegaba gritos ni nada, pero si tenía una forma de cómo hacerme sentir mal". Estas formas de acoso político aumentan cuando un periodo electoral está por empezar. Las vicealcaldesas han señalado que esto se debe a que las ven como amenaza, más incluso si el alcalde ha externado su deseo de reelegirse.

\section{Conclusiones}

La participación política de las mujeres está sujeta a una serie de expresiones de discriminación en los tres momentos de su participación. El puesto de la vicealcaldía ha sido inferiorizado y el abuso del poder hacia este cargo ha generado diversas experiencias discriminatorias hacia las vicealcaldesas. Las vicealcaldesas han vivido acoso político en el periodo anterior e incluso aún siguen recibiendo manifestaciones discriminatorias, por lo tanto, no existe una igualdad real en su participación política.

Las relaciones de poder que se ejercen en un puesto de poder se evidencian cuando una mujer ocupa un puesto en la vicealcaldía, por medio de las expresiones discriminatorias que enfrenta. A pesar de los esfuerzos de Costa Rica en promover el acceso de las mujeres en la política como, por ejemplo, la paridad y la alternancia, es fundamental garantizar espacios libres de discriminación en la política. Asimismo, es necesario analizar los puestos que se les están otorgando a las mujeres o los puestos a los cuales les están permitiendo acceder. Existe aún la incorporación de la mujer en la política para el cumplimiento de una normativa, hecho que queda demostrado en la cantidad de vicealcaldesas que se eligieron para los dos periodos electorales analizados en la investigación.

Por todo lo anterior, existe un reto en garantizar no únicamente la representación de las mujeres en relación con los números, sino también su representación cualitativa, es decir, el ejercicio pleno de su función pública. Son diversas las barreras que han presentado las mujeres en los distintos momentos de su participación política, como, por ejemplo, barreras personales, económicas, legales y socioculturales. La implementación de medidas como la paridad y alternancia es un avance fundamental al velar por la igualdad de acceso de las mujeres a un puesto de elección popular, sin embargo, la representación sustantiva debe ser considerada como agenda nacional con el fin de prevenir, atender y sancionar el acoso político hacia las mujeres que, sin duda, es un obstáculo para ejercer su puesto como vicealcaldesas.

\section{Referencias}

Escalante Herrera, A. C. y Méndez Aguilar, N. (2011). Sistematización de experiencias de acoso político que viven o han vivido las mujeres que ocupan puestos de elección popular en el nivel local [versión de Adobe Acrobat Reader]. Recuperado de https://www. iknowpolitics.org/sites/default/files/acoso_politico_ costa_rica.pdf

Observatorio de Igualdad de Género de América Latina y el Caribe. (2012). La política de paridad y alternancia en la ley electoral de Costa Rica: Un avance en la garantía de la autonomía en la toma de decisiones de las mujeres [versión de Adobe Acrobat Reader]. Recuperado de https://oig.cepal.org/sites/default/files/ politicaelectoral_costarica.pdf

Torres García, I. (2010). Derechos políticos de las mujeres y acoso político como práctica de discriminación. Programa de las Naciones Unidas para los Asentamientos Humanos, ONU- Habitat [versión de Adobe Acrobat Reader]. Recuperado de http://www2.congreso.gob.pe/ sicr/cendocbib/con4_uibd.nsf/DC8E67ECA0DD3F5B05 257E6E00545010/\$FILE/Derechos_politicos_mujeres_ acoso_pol\%C3\%ADtico.pdf

Tribunal Supremo de Elecciones, Código Electoral: Ley $\mathrm{N}^{\circ}$ 8765. (2009). Recuperado de https://www.tse.go.cr/pdf/ normativa/codigoelectoral.pdf 